Original Article

\title{
Association between generalized joint laxity and knee joint movement in female university students
}

\author{
Shinichiro OKa, RPT, PhD ${ }^{1 *}$, Shiori KaWAno, RPT, MS ${ }^{2)}$, TAKeyoshi Shimoda, RPT, MS ${ }^{1)}$, \\ Nozomi Hamachi, RPT, $\mathrm{PhD}^{1)}$, Tsubasa Mitsutake, RPT, $\mathrm{PhD}^{3)}$ \\ 1) Department of Physical Therapy, School of Health Sciences at Fukuoka, International University of \\ Health and Welfare: 137-1 Ohkawa, Fukuoka 831-8501, Japan \\ 2) Division of Medical Service, Mizuho Clinic, Japan \\ 3) Department of Physical Therapy, Fukuoka International University of Health and Welfare, Japan
}

\begin{abstract}
Purpose] This study investigated the association between generalized joint laxity and knee joint movement in female university students. [Participants and Methods] The study included 21 female university students. Generalized joint laxity was measured using the Beighton criteria for joint hypermobility. Acceleration and angular velocities of the tibia during knee extension were measured along three axes using a triaxial accelerometer. Sampling data were expressed as root mean squares. The Mann-Whitney U test was used to determine differences in the acceleration and angular velocities along each axis between the generalized joint laxity and non-generalized joint laxity groups. Spearman's rank correlations were used to confirm the association between these parameters. [Results] The rotational angular velocity was greater in the generalized joint laxity than in the non-generalized joint laxity group, and we observed a significant correlation between Beighton scores and the $\mathrm{X}$-axis angular velocity. Furthermore, rotational angular velocity was positively correlated with anterior-posterior acceleration and extension angular velocity. [Conclusion] These findings suggest that rotational angular velocity of the tibia during knee extension is associated with generalized joint laxity in female university students.

Key words: Benign joint hypermobility syndrome, Rotational instability, Beighton score
\end{abstract}

(This article was submitted Sep. 24, 2021, and was accepted Nov. 13, 2021)

\section{INTRODUCTION}

The terms joint hypermobility, benign joint hypermobility syndrome (BJHS), and generalized joint laxity (GJL) are used to describe a disorder characterized by musculoskeletal symptoms ${ }^{1)}$. BJHS or GJL is associated with a high risk of disability caused by laxity of connective tissue and reduced muscle tone in the extremities and axial skeleton ${ }^{2}$.

Female college students with GJL have been reported to have more disabilities such as knee dislocations, ligament injuries, and sprains ${ }^{3)}$. In particular, it has been pointed out that joint hypermobility may be involved in the occurrence of noncontact primary anterior cruciate ligament (ACL) injuries ${ }^{4)}$ and worse outcomes of reconstruction surgery of ACL ${ }^{5}$, which contributes to anterior-posterior and rotational stability of the knee ${ }^{6}$. Therefore, assessment of knee stability is essential in preventing and returning function following injury.

In clinical practice, assessments of sagittal knee laxity, such as the Lachman test and the anterior drawer test, are extensively used in the diagnosis ${ }^{7)}$ of ACL injuries and reconstruction ${ }^{8)}$ of ACL. Furthermore, methods for evaluating the rotational laxity of the knee have been developed using dynamic radiographs, magnetic resonance imaging (MRI), dynamic radio-stereometry ${ }^{9}$. However, these methods cannot measure rotational instability in the dynamic motion of the knee, where

*Corresponding author. Shinichiro Oka (E-mail: s.oka@iuhw.ac.jp)

(C2022 The Society of Physical Therapy Science. Published by IPEC Inc.

(c) (i) $\odot$ This is an open-access article distributed under the terms of the Creative Commons Attribution Non-Commercial No DerivaCC BY NC ND tives (by-nc-nd) License. (CC-BY-NC-ND 4.0: https://creativecommons.org/licenses/by-nc-nd/4.0/) 
trauma is most likely to occur. In a previous study, a triaxial accelerometer was used for evaluating dynamic knee laxity during the pivot-shift test ${ }^{10)}$. Therefore, the measurement of knee joint motion using a triaxial accelerometer has the potential to determine rotational instability of the knee joint movement.

In this study, we used a triaxial accelerometer to investigate the relationship between GJL and the movement of the lower leg during knee joint extension to assess instability in automatic knee joint motion in healthy young female adults.

\section{PARTICIPANTS AND METHODS}

We recruited 21 female university students aged $\geq 20$ years between April and July 2015 . The inclusion criteria were as follows: (1) no history of injury involving the osteochondral surface, ligament, tendon, capsule, or menisci in the knee joint; and (2) no pain in or treatment of the lower extremities. A total of 21 students were initially recruited and surveyed using a questionnaire and interview. This study was approved by the university ethics review committee (15-Ifh-17) and complied with the Declaration of Helsinki. Before the study commenced, written consent was obtained from all study participants after they were fully informed of the experiment (both orally and in writing).

GJL was measured using the Beighton criteria for joint hypermobility ${ }^{11)}$. Mobility was measured at the spine and bilaterally at the hip, knee, ankle, shoulder, elbow, and wrist, in a total of five positions. The assessment criteria were (1) passive dorsiflexion of the little fingers $\geq 90^{\circ}$ — two points (one point for each hand), (2) passive apposition of the thumbs to the flexor aspects of the forearm - two points (one point for each thumb), (3) hyperextension of the elbows $\geq 10^{\circ}$ — two points (one point for each elbow), (4) hyperextension of the knee $\geq 10^{\circ}$ - two points (one point for each knee), (5) forward flexion of the trunk with knees fully extended so that the palms of the hands rest flat on the floor - one point. For criteria involving joint angle, this was measured using a goniometer. Joint angle measurements were performed by one operator and recorded by another operator. The cut-off score for the diagnosis of GJH was $\geq 5$ points according to the Beighton score appropriate to young adults ${ }^{12)}$.

Knee joint movement was measured using a triaxial accelerometer (TSDN121, ATR promotions Inc., Kyoto, Japan) with a sampling rate of $250 \mathrm{~Hz}$. Linear acceleration and angular velocity in three axes were recorded. The sensor was fixed with velcro on the tibial rough surface with the participants. The participants sat on a seat with a backrest and began with $90^{\circ} \mathrm{knee}$ flexion. They then raised the knee joint to an extended position 10 times at a frequency of $1.0 \mathrm{~Hz}$. The acceleration and angular velocity of the middle six times were recorded, excluding the first two and last two. The extracted data were expressed as root mean squares. Acceleration of the lower limbs in the X-axis indicates the vertical direction, Y-axis the horizontal direction, and Z-axis the anterior-posterior direction. The angular velocity of the lower leg in the $\mathrm{X}$-axis represented rotation, Y-axis knee extension, and Z-axis lateral flexion.

All analyses were conducted using SPSS statistics (ver. 25.0; IBM Corp., Armonk, NY, USA). The Shapiro-Wilk test was used to confirm that the data were distributed normally. Mann-Whitney $U$ tests were used to examine differences between the GJL and the non-GJL group in acceleration and angular velocity in each direction. Spearman's rank tests were used to determine the relationship between the Beighton scores, acceleration, and angular velocity for each plane of lower limb movement. Significance was accepted at a p-value $<0.05$.

\section{RESULTS}

Table 1 shows the basic characteristics and Beighton scores of the participants. The average age of the participants was 21.6 years old, and they had an average body mass index of 21.6. Based on the Beighton score, 7 and 14 people were found to have GJL and non-GJL, respectively. There were no differences in any characteristic between the GJL and non-GJL groups by independent t-test (except their Beighton scores). Table 2 describes the acceleration and angular velocities for each plane in the whole cohort and the two subgroups. Most of these parameters showed no differences between the GJL and non-GJL groups by Mann-Whitney $U$ test, but the $\mathrm{X}$-axis angular velocity was faster in the GJL group than in the non-GJL group (Table 2).

Correlations between these results are shown in Table 3. There was a significant correlation between Beighton score and $\mathrm{X}$-axis angular velocity $(\mathrm{r}=0.485$, $\mathrm{p}$-value $=0.026)$. Furthermore, $\mathrm{X}$-axis angular velocity was positively correlated with $\mathrm{Z}$-axis acceleration $(\mathrm{r}=0.579$, $\mathrm{p}$-value $=0.006)$ and $\mathrm{Y}$-axis angular velocity $(\mathrm{r}=0.517, \mathrm{p}$-value $=0.016)$. There were no other significant correlations between the parameters.

\section{DISCUSSION}

This study showed that when knee joint movement was measured during dynamic motion, young female adults with GJL had faster X-axis angular velocity than those without GJL. Moreover, the X-axis angular velocity positively correlated with Beighton scores, Z-axis acceleration, and Y-axis angular velocity. These findings indicate that the triaxial accelerometer can quantitatively and objectively evaluate the rotational instability during knee joint motion in young female adults.

The $\mathrm{X}$-axis angular velocity showed positive correlation with $\mathrm{Z}$-axis acceleration and Y-axis angular velocity. Knee joint movement is a combination of movements in the sagittal and horizontal planes. In particular, knee joint rotation is a motion 
in the vertical plane relative to the long axis of the tibia ${ }^{13)}$. Therefore, the rotational motion of the tibia cannot be performed independently; it is biomechanically linked with the flexion-extension motion ${ }^{14,15)}$. During knee extension, the articular surface of the tibia slides and rolls forward over the femoral condyle, and the knee joint is fixed with approximately $10^{\circ}$ of external rotation in full extension ${ }^{16)}$. In the final $30^{\circ}$ of extension, there is a twist-this turning and locking movement is called the screw home movement (external rotation). In the present study, the sensor placed on the tibia captured its long axis direction (the $\mathrm{X}$-axis), its transverse direction (the $\mathrm{Y}$-axis), and its anterior-posterior direction (the Z-axis). The observed correlation between $\mathrm{X}$-axis angular velocity and both Z-axis acceleration and Y-axis angular velocity suggests that this method can measure compound motions (Z-axis acceleration for forward sliding, Y-axis angular velocity for rolling, and $\mathrm{X}$-axis angular velocity for external rotation) during knee joint extension.

$\mathrm{X}$-axis angular velocity positively correlated with Beighton scores, which were significantly higher in the GJL group than the non-GJL group. A primary stabilizer of the knee, the ACL, provides both rotatory and translational support ${ }^{6)}$. The load on the ACL during knee joint motion is greatest between $10^{\circ}$ and $50^{\circ}$ of knee flexion (generally peaking between $10^{\circ}$ and $30^{\circ}$ ) and less between $50^{\circ}$ and $100^{\circ}$ of knee flexion ${ }^{17)}$. Both anterior and rotational static knee laxity have been reported in healthy individuals ${ }^{18}$. Further, women with GJL have instability in head extension and rotation while standing, putting them at risk for musculoskeletal injuries in sports requiring these movements ${ }^{19}$ ). GJL is an identified risk factor for ACL injury; Myer

Table 1. Participant characteristics

\begin{tabular}{lccc}
\hline & Total $(\mathrm{n}=21)$ & GJL $(\mathrm{n}=7)$ & non-GJL $(\mathrm{n}=14)$ \\
\hline Age $($ years $)$ & $21.6(0.5)$ & $21.9(0.4)$ & $21.4(0.5)$ \\
Height $(\mathrm{m})$ & $1.57(0.08)$ & $1.56(0.06)$ & $1.57(0.09)$ \\
Weight $(\mathrm{kg})$ & $53.3(6.7)$ & $56.0(5.3)$ & $51.9(7.0)$ \\
BMI $\left(\mathrm{kg} / \mathrm{m}^{2}\right)$ & $21.6(1.5)$ & $22.9(1.2)$ & $20.9(1.2)$ \\
Beighton score & $5.0(2.0)$ & $6.1(1.4)$ & $2.7(0.5)$ \\
\hline
\end{tabular}

Data are presented as mean (SD). Comparisons were made using an independent t-test.

GJL: generalized joint laxity; BMI: body mass index.

Table 2. Results of acceleration and angular velocity during knee extension

\begin{tabular}{lccc}
\hline & Total $(\mathrm{n}=21)$ & GJL $(\mathrm{n}=7)$ & non-GJL $(\mathrm{n}=14)$ \\
\hline Acceleration $(\mathrm{m} / \mathrm{sec})$ & & & \\
X-Vertical & $103.6(102.7-105.3)$ & $103.5(101.6-105.9)$ & $103.6(103.5-105.1)$ \\
Y-Horizontal & $18.9(9.5-22.6)$ & $19.1(9.5-25.6)$ & $18.9(10.0-19.6)$ \\
Z-Anterior-posterior & $18.8(11.7-18.9)$ & $23.3(11.7-34.0)$ & $14.6(12.6-23.4)$ \\
Angular velocity $(\% \mathrm{sec})$ & & & \\
X-Rotation & $9.8(6.1-22.6)$ & $13.3(8.5-16.9)^{*}$ & $6.2(5.8-8.5)$ \\
Y-Extension & $59.4(53.0-79.6)$ & $65.3(47.2-89.8)$ & $55.8(54.3-59.5)$ \\
Z-Lateral flextion & $10.4(6.3-12.7)$ & $9.7(6.3-12.1)$ & $10.8(6.9-19.3)$ \\
\hline
\end{tabular}

Median value (range), Mann-Whitney U test, ${ }^{*} \mathrm{p}<0.05$

GJL: generalized joint laxity.

Table 3. Correlations among Beighton score, acceleration, and angular velocity during knee extension

\begin{tabular}{lccccccc}
\hline & & \multicolumn{3}{c}{ Acceleration } & \multicolumn{3}{c}{ Angular velocity } \\
\cline { 3 - 7 } & & $\mathrm{X}$ & $\mathrm{Y}$ & $\mathrm{Z}$ & $\mathrm{X}$ & $\mathrm{Y}$ & $\mathrm{Z}$ \\
\hline Beighton score & & 0.264 & -0.047 & 0.084 & $0.485^{*}$ & 0.155 & -0.139 \\
Acceleration & $\mathrm{X}$ & & & & & & \\
& $\mathrm{Y}$ & -0.129 & & & & & \\
& $\mathrm{Z}$ & -0.146 & -0.053 & & & & \\
Angular velocity & $\mathrm{X}$ & -0.041 & 0.142 & $0.579^{* *}$ & & & \\
& $\mathrm{Y}$ & -0.321 & -0.227 & 0.358 & $0.517^{*}$ & & \\
& $\mathrm{Z}$ & -0.282 & -0.338 & -0.136 & 0.049 & 0.359 & \\
\hline
\end{tabular}

$\mathrm{n}=21$, Spearman's signed-rank test, $* * \mathrm{p}<0.01,{ }^{*} \mathrm{p}<0.05$.

Acceleration: X-Vertical, Y-Horizontal, Z-Anterior-posterior.

Angular velocity: X-Rotation, Y-Extension, Z-Lateral flextion. 
et al. ${ }^{20)}$ found that the risk of ACL injury in female college athletes was 4.78 times higher in those with knee hyperextension and 4.03 times higher in those with left-right difference in anterior-posterior knee translation motion. In men too, GJL is associated with unilateral ACL injury; the odds ratio for ACL injury in the presence of GJL is 1.3 according to a systematic review $^{21)}$. This suggested that those with high joint laxity had the rotational instability during knee joint extension. The findings of this study will contribute to the prevention of trauma in young females with instability in the rotational direction of the knee joint and to the evaluation of knee joint stability after ACL injury and reconstruction.

A limitation of this study is that the knee joint extension motion was measured in an open kinetic chain. During sports activities, ACL injury is caused by complex movements. Another potential limitation could be the small sample size and limited age of the participants. In future research, we aim to measure GJL and knee joint motion during sporting activities in order to contribute to the prevention of ACL injury.

In conclusion, we have shown that unreported GJL is associated with an increase in rotational angular velocity of the tibia during knee extension in healthy young women. These findings contribute to the understanding of knee injuries and diseases, and can be used to develop prevention strategies and improve treatment outcomes.

\section{Conflicts of interest}

There is no conflict of interest.

\section{REFERENCES}

1) Castori M, Tinkle B, Levy H, et al.: A framework for the classification of joint hypermobility and related conditions. Am J Med Genet C Semin Med Genet, 2017, 175: 148-157. [Medline] [CrossRef]

2) Grahame R: Joint hypermobility and genetic collagen disorders: are they related? Arch Dis Child, 1999, 80: 188-191. [Medline] [CrossRef]

3) Reuter PR, Fichthorn KR: Prevalence of generalized joint hypermobility, musculoskeletal injuries, and chronic musculoskeletal pain among American university students. PeerJ, 2019, 7: e7625. [Medline] [CrossRef]

4) Uhorchak JM, Scoville CR, Williams GN, et al.: Risk factors associated with noncontact injury of the anterior cruciate ligament: a prospective four-year evaluation of 859 West Point cadets. Am J Sports Med, 2003, 31: 831-842. [Medline] [CrossRef]

5) Branch TP, Siebold R, Freedberg HI, et al.: Double-bundle ACL reconstruction demonstrated superior clinical stability to single-bundle ACL reconstruction: a matched-pairs analysis of instrumented tests of tibial anterior translation and internal rotation laxity. Knee Surg Sports Traumatol Arthrosc, 2011, 19: 432-440. [Medline] [CrossRef]

6) Zlotnicki JP, Naendrup JH, Ferrer GA, et al.: Basic biomechanic principles of knee instability. Curr Rev Musculoskelet Med, 2016, 9: 114-122. [Medline] [CrossRef]

7) Meredick RB, Vance KJ, Appleby D, et al.: Outcome of single-bundle versus double-bundle reconstruction of the anterior cruciate ligament: a meta-analysis. Am J Sports Med, 2008, 36: 1414-1421. [Medline] [CrossRef]

8) van Eck CF, Loopik M, van den Bekerom MP, et al.: Methods to diagnose acute anterior cruciate ligament rupture: a meta-analysis of instrumented knee laxity tests. Knee Surg Sports Traumatol Arthrosc, 2013, 21: 1989-1997. [Medline] [CrossRef]

9) Colombet P, Jenny JY, Menetrey J, et al. French Arthroscopy Society (SFA): Current concept in rotational laxity control and evaluation in ACL reconstruction. Orthop Traumatol Surg Res, 2012, 98: S201-S210. [Medline] [CrossRef]

10) Lopomo N, Zaffagnini S, Signorelli C, et al.: An original clinical methodology for non-invasive assessment of pivot-shift test. Comput Methods Biomech Biomed Engin, 2012, 15: 1323-1328. [Medline] [CrossRef]

11) Beighton P, Solomon L, Soskolne CL: Articular mobility in an African population. Ann Rheum Dis, 1973, 32: 413-418. [Medline] [CrossRef]

12) Malfait F, Francomano C, Byers P, et al.: The 2017 international classification of the Ehlers-Danlos syndromes. Am J Med Genet C Semin Med Genet, 2017, 175: 8-26. [Medline] [CrossRef]

13) Churchill DL, Incavo SJ, Johnson CC, et al.: The transepicondylar axis approximates the optimal flexion axis of the knee. Clin Orthop Relat Res, 1998, (356): 111-118. [Medline] [CrossRef]

14) Patel VV, Hall K, Ries M, et al.: A three-dimensional MRI analysis of knee kinematics. J Orthop Res, 2004, 22: 283-292. [Medline] [CrossRef]

15) Standring S: Gray's anatomy: the anatomical basis of clinical practice, 41st ed. St Louis: Elsevier, 2015.

16) Ishii Y, Terajima K, Terashima S, et al.: Three-dimensional kinematics of the human knee with intracortical pin fixation. Clin Orthop Relat Res, 1997, (343): 144-150. [Medline]

17) Escamilla RF, Macleod TD, Wilk KE, et al.: Anterior cruciate ligament strain and tensile forces for weight-bearing and non-weight-bearing exercises: a guide to exercise selection. J Orthop Sports Phys Ther, 2012, 42: 208-220. [Medline] [CrossRef]

18) Mouton C, Seil R, Meyer T, et al.: Combined anterior and rotational laxity measurements allow characterizing personal knee laxity profiles in healthy individuals. Knee Surg Sports Traumatol Arthrosc, 2015, 23: 3571-3577. [Medline] [CrossRef]

19) Aydın E, Metin Tellioğlu A, Kurt Ömürlü İ, et al.: Postural balance control in women with generalized joint laxity. Turk J Phys Med Rehabil, 2017, 63: 259-265. [Medline] [CrossRef]

20) Myer GD, Ford KR, Paterno MV, et al.: The effects of generalized joint laxity on risk of anterior cruciate ligament injury in young female athletes. Am J Sports Med, 2008, 36: 1073-1080. [Medline] [CrossRef]

21) Sundemo D, Hamrin Senorski E, Karlsson L, et al.: Generalised joint hypermobility increases ACL injury risk and is associated with inferior outcome after ACL reconstruction: a systematic review. BMJ Open Sport Exerc Med, 2019, 5: e000620. [Medline] [CrossRef] 